\title{
Esclarecendo o caso dos homônimos Manoel de Abreu*
}

\author{
Clarifying the case of two people \\ with the same name of Manoel de Abreu
}

\section{Rubens Bedrikow}

Médico sanitarista e clínico; professor, Faculdade de Ciências Médicas/Departamento de Saúde Coletiva/Universidade Estadual de Campinas.

Rua Tessália Vieira de Camargo, 126 13083-887 - Campinas - SP - Brasil rubedrikow@yahoo.com.br
BEDRIKOW, Rubens. Esclarecendo o caso dos homônimos Manoel de Abreu. História, Ciências, Saúde - Manguinhos, Rio de Janeiro, v.22, n.3, jul.-set. 2015, p.1007-1018.

\section{Resumo}

Recupera-se aqui um episódio curioso da história da medicina brasileira envolvendo dois médicos homônimos nos anos de 1936 e 1937. Manoel Dias de Abreu deixou como seu mais relevante legado um método radiológico para o diagnóstico da tuberculose - a abreugrafia. Manoel de Abreu Campanario escreveu A medicina no interior. A semelhança entre os dois nomes gerou tamanha confusão, que algumas pessoas acreditaram ser Campanario um pseudônimo. Tal engano fez com que Manoel Dias de Abreu encaminhasse uma declaração-consulta à Sociedade de Medicina e Cirurgia, que prontamente criou uma comissão encarregada de examinar o caso. A solução veio com a carta esclarecedora de Campanario.

Palavras-chave: Manoel Dias de Abreu (1894-1962); Manoel de Abreu Campanario (1906-1994); abreugrafia; história da radiologia; medicina no interior.

\section{Abstract}

A curious episode in the history of Brazilian medicine is retold here, involving two physicians with the same name, between 1936 and 1937. The most important legacy left by Manoel Dias de Abreu was a method of radiography to diagnose tuberculosis - mass miniature radiography (abreugraphy). Manoel de Abreu Campanario wrote A medicina no interior (Medicine from the interior). The similarities between the two names created such confusion that some people believed that Campanario was a pseudonym. This case of mistaken identity led Manoel Dias de Abreu to send a consultation-statement to the Brazilian Society for Medicine and Surgery, which immediately created a commission to examine the case. The letter of clarification sent by Campanario resolved the issue.

Keywords: Manoel Dias de Abreu (1894-1962); Manoel de Abreu Campanario (1906-1994); abreugraphy; history of radiology; medicine in the interior. 


\section{O radiologista clínico}

Em 25 de maio de 1957, Manoel de Abreu Campanario entregou para publicação o manuscrito que três dias antes apresentara no Departamento de Radiologia e Eletricidade Médica da Associação Paulista de Medicina, intitulado "Acerca do relatório radiológico" (Campanario, nov. 1957). Passaram-se mais de 40 anos até que eu descobrisse esse texto na Biblioteca Dr. Augusto Meirelles Reis, da Faculdade de Ciências Médicas da Santa Casa de São Paulo.

O título desperta curiosidade, pois, se de um lado a radiologia iniciada com Röentgen em 1895 ainda desfruta de justo prestígio e permanece como um dos maiores sustentáculos da propedêutica contemporânea, de outro, ocupa um lugar relativamente discreto no currículo de grande parte das escolas de medicina, ficando seu ensino reservado aos cursos extracurriculares ou de pós-graduação. Por isso, raramente os futuros médicos discutem com seus professores a respeito do relatório radiológico.

Para Campanario (nov. 1957, p.403), "não se poderá compreender um radiologista que não seja clínico. A radiologia é pura semiótica clínica. O aparelho não passa do prolongamento dos sentidos. Os raios X são o prolongamento da palpação, da percussão, da ausculta, da semiótica, enfim. Fora desse postulado o radiologista não passará de um técnico, isto é, de um roentgenfotógrafo".

\section{Manoel Dias de Abreu}

Com o afã de conhecer mais sobre o médico que apregoara a união da radiologia com a clínica, procurei, naquela mesma biblioteca, fundada em 1954 graças à inestimável contribuição de Sinésio Rangel Pestana, alguma informação. Foi então que me deparei com o livro Vida e obra de Manoel de Abreu: o criador da abreugrafia, escrito por Itazil Benício dos Santos (1963). O exemplar pertenceu ao professor Adauto Barbosa Lima, ex-diretor da Faculdade de Ciências Médicas da Santa Casa de São Paulo, conforme assegura a dedicatória de próprio punho da viúva de Manoel de Abreu (Bedrikow, jan.-fev. 2001). À medida que lia os capítulos, dava-me conta de que Manoel de Abreu deveria figurar entre as principais celebridades da medicina nacional de todos os tempos. O método por ele criado em 1936, primeiro apelidado de "roentgenfotografia", mas rebatizado de "abreugrafia", por sugestão de Ary Miranda, presidente do primeiro Congresso Nacional de Tuberculose, em 1939, solucionou um grave problema que desafiava médicos de quase todo o planeta: como fazer o diagnóstico em massa da tuberculose pulmonar. Para Manoel de Abreu (dez. 1936, p.315), a grande e única vantagem do novo método era a economia.

Enquanto a radiografia do tórax é feita em filmes $30 \times 40 \mathrm{~cm}$, logo muito dispendiosos e de dispendiosa manipulação, a roentgenfotografia é feita em filmes de cerca de $2,4 \times 3,6 \mathrm{~cm}$, cuja superfície é mais de duzentas vezes menor, pois os primeiros têm camada sensível de ambos os lados. Seu custo é mais de cem vezes menor, quer dizer, quase nulo, permitindo sua aplicação em larga escala. A radiografia comum, ao contrário, é de preço elevadíssimo, o que explica a limitação do seu emprego.

Manoel Dias de Abreu nasceu em São Paulo, em 1892, e concluiu o curso na Faculdade de Medicina do Rio de Janeiro em 1913. Entre 1915 e 1922, estagiou nos serviços de radiologia 


\section{REVISTA}

DA

\section{ASSOCIAÇÃO PAULISTA DE MEDICINA}

REDACTORES:

DRS. J. N. v. SONNLEITHNER, S. HERMETO JUNIOR E J. M. CABELLO CAMPOS

VOLUME IX Dezembro de 1936 NUMERO 6

\section{RÖNTGEN - PHOTOGRAPHIA. (*)}

Processo e apparelho de rôntgen-photographia. Tuberculose pulmonar. Cadastro social. Radiographia e radioscospia. Röntgenphotographia collectiva.

\section{DR. MANOEL DE ABREU}

Principio - Photographia das imagens do écran fluoroscopico ou fixação photographica das imagens radioscopicas. Desde muito já se fizeram tentativas no sentido de protographar o écran para a realização da radio-cinematographia chamada indirecta e nós mesmos em 1920, em Paris, tentamos sem successo obter röntgen-photographias, como se verifica neste trecho do nosso livro "Radiodiagnostic dans la Tuberculose pulmonaire", prefaciado por Rist e editado em 1921, pag. 50:

"Il est regrettable que les premières recherches tentées par Guilleminor dans cette voie n'aient pas eté poursuivies comme on etait en droit de l'esperer".

" $\mathrm{La}$ lumiére trés faible de la fluorescence de l'écran est loin d'être suffisante pour impressioner les plaques aux sels d'argent dans une minime fraction de seconde; tel est du moins le résultat de nos experiences".

A radiocinematographia indirecta foi objecto de numerosas tentativas, mas sómente em 1935, no Congresso de Bruxellas, Georges Djian de um lado e RUSSEL e REYNOLDS, de outro, apresentaram apparelhos que parecem satisfazer praticamente.

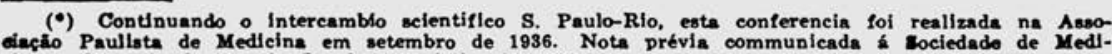
cina. Cirurgia do Rio de Janeiro em julho de 1936. 


\section{VIDA E OBRA DE \\ MANOEL DE ABREU \\ O CRIADOR DA ABREUGRAFIA}

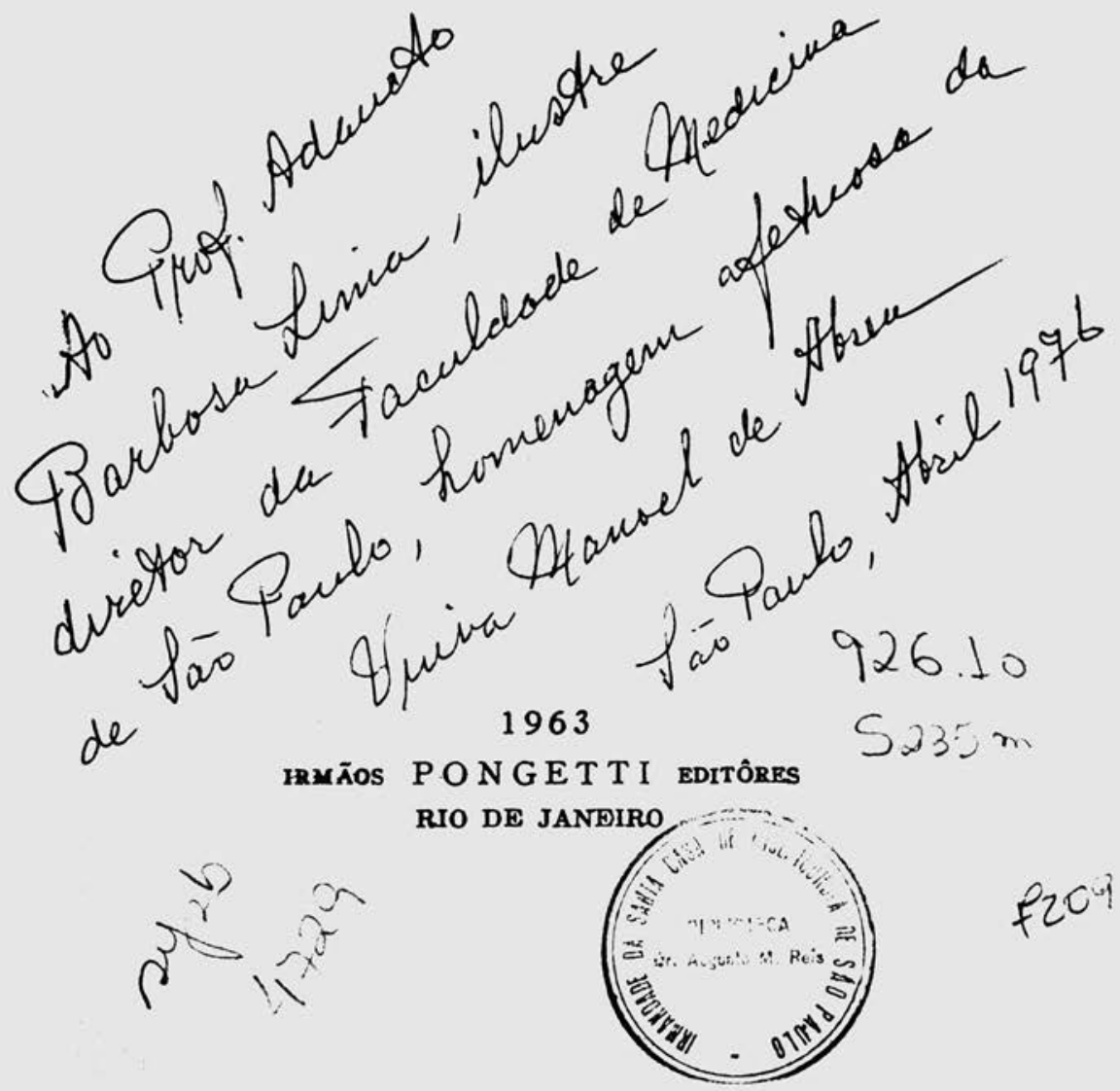

Figura 2: Livro de Itazil Benício dos Santos sobre Manoel de Abreu, com a dedicatória da esposa de Manoel de Abreu ao diretor da Faculdade de Medicina de São Paulo, professor Adauto Barbosa Lima 
de três renomados hospitais franceses: Nouvel Hôpital de la Pitié, Hôtel-Dieu e Hôpital Laennec. Seu livro Radiodiagnostic dans la tuberculose pleuro-pulmonaire (Abreu, 1921), publicado pela editora Masson, em 1921, deu início à sua projeção internacional, consolidada após a descoberta da roentgenfotografia. Seu currículo enriqueceu-se ainda com a teoria da radiogeometria, a técnica das tomografias simultâneas e a pesquisa do bacilo de Koch no lavado traqueobroncoalveolar. Recebeu homenagens reservadas a poucos: o Dia Nacional da Abreugrafia (4 de janeiro), instituído em 1958 pelo então presidente da República Juscelino Kubitschek. Foi homenageado ainda pela Sociedade Brasileira de Abreugrafia, pela Revista Brasileira de Abreugrafia e pela Sociedade Internacional de Roentgenfotografia. Após seu falecimento, por câncer de pulmão, em 1962, outras homenagens sucederam-se. No dia 5 de fevereiro de 1962, durante reunião da Mesa Administrativa da Irmandade de Misericórdia de São Paulo, sob a presidência do provedor Christiano Altenfelder Silva, foi lida a seguinte proposta:

A Diretoria Clínica, em nome do corpo clínico deste hospital, deseja prestar homenagem à memória do professor Manoel de Abreu. Manoel de Abreu era paulista de nascimento e nome internacional que criou a chamada abreugrafia, extraordinária não somente pelo valor intrínseco, como, notadamente, pela repercussão que trouxe para a vida médica social de todo o mundo. A Santa Casa de São Paulo, que utiliza a abreugrafia todos os dias em seus hospitais, seja para selecionar casos, seja para orientar os internamentos, não pode deixar de prestar homenagem a esse paulista que elevou e dignificou a sua terra e a sua gente. Propomos que seja inaugurado o retrato do professor Manoel de Abreu no Departamento de Abreugrafia deste hospital, ocasião em que a Diretoria Clínica e a Mesa Administrativa prestarão as homenagens ao grande cientista nacional, numa manifestação de gratidão e de exaltação de sua grande obra (ISCMSP, 5 fev. 1962).

Mais recentemente, a Faculdade de Ciências Médicas da Santa Casa de São Paulo criou o Prêmio Manoel de Abreu para o melhor trabalho apresentado anualmente no Congresso Médico-Acadêmico.

Causou-me perplexidade descobrir que o criador da abreugrafia não era o mesmo Manoel de Abreu que escrevera o interessante artigo "Acerca do relatório radiológico". O primeiro fora batizado Manoel Dias de Abreu, enquanto seu homônimo, também radiologista, tinha por nome Manoel de Abreu Campanario. Quem seria, então, este último?

\section{Manoel de Abreu Campanario}

O endereço para correspondência no pé da página do artigo publicado na Revista da Associação Paulista de Medicina, em 1957, pertence atualmente à filha de Campanario, e, graças à sua inegável boa vontade e gentileza, fui capaz de saciar a curiosidade sobre a vida de seu pai.

Terceiro filho de Joaquim de Abreu Campanario - descendente de portugueses - e Dinorah Teixeira Leite de Abreu Campanario, de família de fazendeiros cafeicultores, nasceu em Pirapetinga (MG), em 10 de novembro de 1906. O sobrenome Campanario origina-se de corsários holandeses que aportaram na Ilha da Madeira. Entre 1913 e 1914, frequentou escola primária em Paraoquena, hoje distrito de Santo Antonio de Pádua (RJ). Em seguida, estudou no Internato Ateneu Victor Hugo, em Providência, região montanhosa na divisa 
de Minas Gerais com o estado do Rio de Janeiro. Prosseguiu os estudos no Colégio Dom Pedro II, na cidade do Rio de Janeiro (1918 a 1920), e no Internato Ginásio Leopoldinense (MG, entre 1921 e 1925), estabelecimento esse fundado pela família Junqueira e que recebia fundamentalmente os filhos dos fazendeiros da região. O pai de Campanario antevia um futuro de risco para as fazendas de café no Brasil e, por isso, fez questão de que todos os filhos estudassem. Diplomou-se pela Faculdade Federal de Medicina de Minas Gerais, em 1931. Nos dois anos seguintes, trabalhou como sanitarista no Serviço de Saúde Pública do Espírito Santo e dedicou-se ao estudo da malária entre os índios da região, graças à bolsa da Fundação Rockefeller. Dessa aventura resultou sua desenvoltura com a língua tupi-guarani e a coleção de pios de que tanto se orgulhava. Em 1933, radicou-se em Santo Antônio de Pádua (RJ), onde seu pai possuía uma fazenda e onde exerceu clínica médica e cirurgia, além de contribuir ativamente para a construção do primeiro nosocômio da cidade, o Hospital Manoel Ferreira. No início da década de 1940, transferiu-se para São Paulo. Provavelmente, acompanhou a tendência de esvaziamento do campo e inchaço dos grandes centros urbanos decorrente do declínio da cafeicultura e do crescimento da industrialização. Aos 42 anos, contraiu poliomielite e, impossibilitado de seguir operando, passou a dedicar-se à radiologia. Trabalhou com os renomados professores Benedito Montenegro e Alípio Corrêa Neto, na Santa Casa. Seu aperfeiçoamento na área de radiologia esteve sob a égide dos mestres Raphael de Barros e Cássio Martins Villaça. Após o afastamento deste último, assumiu a direção do serviço de raios $X$ das segunda e terceira enfermarias de homens. Não foi por mera coincidência



Figura 3: Manoel de Abreu Campanario 
que a rua em que morava levava o nome do mestre que substituíra. Com efeito, após o falecimento do professor Villaça, requereu, mediante carta endereçada ao então governador do estado - Jânio Quadros -, mudança de nome da rua Um para rua Cássio Martins Villaça. Para sua surpresa, o pedido foi atendido em apenas uma semana. Além das atividades no seu consultório particular - instalado inicialmente à rua Sete de Abril -, exerceu radiologia nos hospitais Santa Cruz, Central da Sorocabana e Nove de Julho. Acreditava que para ser um bom radiologista era preciso ser também um bom clínico. Em 1965, encetou árdua pesquisa que culminou com a publicação do livro Hans Staden: o homem e a obra (Campanario, 1980), rica contribuição para a etnografia dos índios brasileiros no começo da fase colonial. O reconhecimento veio com o Prêmio Clio de História da Academia Paulista de História (1982) e a outorga do título de cidadão itanhaense em sessão solene na Câmara Municipal de Itanhaem, em 1983. Além da medicina, suas paixões foram a pesca, a caça e as reuniões com amigos. Carismático e divertido, costumava organizar viagens ao rio Araguaia. Seu interesse pela caça proporcionou-lhe o privilégio de ser presenteado com uma arma do general Rondon. Compartilhou seu conhecimento sobre os índios e sua paixão pelos animais com os amigos Villas-Boas. O naturalista e escritor Francisco de Barros Júnior era amigo de Campanario, e o homenageou batizando personagens de suas histórias sobre caça e pesca com os nomes dos filhos do amigo. Faleceu em 7 de setembro de 1994, em razão de cardiopatia (Bedrikow, 20 set. 2000; Campanario, 18 out. 1991; Dr. Manoel..., dez. 1991, p.39-40).

O ano de 1936 foi singular para ambos os radiologistas. Enquanto Manoel Dias de Abreu inventava a roentgenfotografia, seu homônimo publicava o livro A medicina no interior (Campanario, 1936). Nesse livro, Campanario tece críticas ao método pedagógico adotado no ensino médico, reprova a especialização prematura sem o adequado domínio da clínica geral, repudia a homeopatia, discute o aborto, defende a eutanásia como medida extrema de alívio do sofrimento, condena o segredo médico absoluto que traz prejuízo para terceiros ou para a sociedade como um todo e ressalta as dificuldades do exercício da obstetrícia e da cirurgia na roça.

A medicina no interior projetou o autor muito além das fronteiras de Santo Antonio de Pádua. Na sua coluna do jornal $A$ Noite, Celso Vieira (25 set. 1936) pondera que "do pequeno livro sem ornatos ressaem vários conceitos fundamentais para a estrutura social deste país e a existência das novas gerações". Reproduz o inconformismo de Campanario frente ao pauperismo do interior do país e às precárias condições de trabalho do médico naquelas paragens:

a tragédia do médico da roça foi lançada aos quatro ventos pelo dr. Campanario, num texto enérgico e vibrante. Nenhum quadro mais desolador. Sem instrumentos, sem laboratórios, sem apreço e estímulo, incompreendido no meio rural, solitário entre os homens bravios, hostilizado por ignorância, maledicência ou inveja, defrontando superstições, preconceitos, violências, a inépcia ou a dureza de almas obtusas ou perversas, o clínico do interior há de fazer milagres na cirurgia, na obstetrícia, na terapêutica. Ao matuto não basta o exame nem a receita, gratuitamente: se o esculápio não lhe dá um vidro de remédio, ou dinheiro para o comprar, é descaridoso e nulo. Chamado apenas o médico em lances extremos, sofre ainda a injúria dos pobres e a calúnia dos ricos, que muitas vezes não lhe pagam visitas e operações. Tem como inimigos profissionais o raizeiro, o feiticeiro, o curandeiro, o espírita homeopata e o boticário gananciosos, todos quantos se entregam nas aldeias ao exercício ilegal da medicina. 
Depara obstáculos insuperáveis à cirurgia de urgência. Vê o tratamento impossibilitado pela inobservância das prescrições de repouso e dieta; pela subalimentação da máquina humana; pelo falso pudor das mulheres; pela rebeldia dos enfermos, descontentes e insubmissos. Seu anedotário é tão expressivo quanto seu tormento... Mas o eterno diálogo no interior do Brasil, entre o doente e o médico, põe quase sempre diante de uma impossibilidade a esperança da cura. Porque não há medicina preventiva nem curativa naquelas paragens; amando a solidão, vivem e morrem os trabalhadores em casebres ou palhoças infectas, lares sumidos no deserto; não se edificam ali hospitais nem funcionam postos cirúrgicos, disseminados através dos latifúndios; sem a intervenção da cirurgia, perdem-se quase todos os doentes pobres de apendicite, hérnia estrangulada, úlcera gástrica; desamparados como esses, acabam da mesma sorte os feridos, vítimas de golpes e tiros no abdômen; e ante o quadro regional das populações desnutridas, o mais absurdo, mais doloroso dos aspectos de Canaã brasileira, afirma o doutor Campanario que a subalimentação é o maior perigo nacional, excedendo o flagelo das endemias, da politicalha e das lutas civis (Vieira, 25 set. 1936).

O prefácio do livro coube ao catedrático de química biológica Baeta Vianna. Em carta datada de $1^{\circ}$ de julho de 1936 , comenta a tarefa realizada:

Vai resumido como me pediu. Fi-lo há pouco, em substituição a um outro que fui compondo à medida que folheava seu livro magnífico; é claro que tão inferior à obra que ela estava, que não podia resistir ao paralelo. Inutilizei-o, felizmente para nós dois.

Ocorreu-me falar do autor em vez da obra, e o que eu disse eu sustento... receba do amigo gratíssimo um apertado abraço de parabéns pela obra que o irá imortalizar como um pensador e um literato de talento incomum (Vianna, 1 jul. 1936).

Um exemplar do livro foi ofertado ao então presidente Getúlio Vargas, que transmitiu os agradecimentos por intermédio do secretário da Presidência Luiz Vergara (Vergara, 22 set. 1936).

O professor Silva Melo (16 jun. 1937) manifestou-se da seguinte forma:

Rio, 16.6.1937.

Meu caro colega dr. Campanario,

Tive muita satisfação em receber a sua opinião sobre os 'Problemas do ensino médico', principalmente por se tratar de um espírito que parece ver bem as realidades da vida. Já tive a ocasião de ler o seu excelente livro - A medicina no interior... Vimos as coisas com os mesmos olhos, e isso vale, para ambos, como uma garantia quanto à sua exata observação. Aguardando a oportunidade para conhecê-lo pessoalmente aqui no Rio, peço aceitar a expressão de meus agradecimentos pelas suas afetuosas palavras. Colega e sincero admirador.

Em papel timbrado da Ação Integralista Brasileira, Plínio Salgado (28 jun. 1937), versa sobre o livro de Campanario:

Rio, 28 de junho de 1937.

Prezado patrício dr. Manoel de Abreu Campanario,

Anteontem passei boa parte da madrugada lendo o seu livro A medicina no interior e resolvi responder pessoalmente a sua cartinha de $1^{\circ}$ do corrente. Gostei muitíssimo do seu livro, o qual, na sua simplicidade, descortina o vasto panorama da função 
social da medicina. Ideias, que a observação do interior brasileiro me havia sugerido, fortaleceram-se em meu espírito, diante de suas páginas. O plano que tenho em mente ver um dia executado, em todo Brasil, e que já deixei esboçado em meu manifestoprograma, quando desloquei do Ministério da Educação para o da Economia Nacional a Saúde Pública, evidencia a importância que dou ao setor da medicina como condição de valorização do fator mais importante da economia: o homem. Tudo está por fazer nesse campo. Vê o patrício as razões que determinaram meu vivo interesse pelo seu livro, que li com prazer. Algum dia havemos de conversar melhor. Receba as felicitações.

O jornal O Estado, de $1^{\circ}$ de outubro de 1936, publicou matéria intitulada "A medicina no interior: um livro interessante do dr. Manoel de Abreu Campanario":

Sacerdote da sua profissão, tendo pela ciência médica verdadeiro entusiasmo, o dr. Campanario conhece até os mais distantes recantos do município de Pádua, bem como os demais dessa região do norte do estado. Esse conhecimento ele conseguiu levado pela profissão, tendo, assim, nitidamente nos olhos todo esse panorama rústico da terra pobre de civilização, todos os empecilhos e horrores das caminhadas pela noite adentro, pelo tempo afora, no mister nobre de curar, de minorar o sofrimento alheio... Interessa a todos, delicia, agrada ao leitor, pondo-lhe ainda diante dos olhos, cheios desse encantamento das cidades civilizadas, aquela tremenda luta do médico da roça, vivida diariamente, quase anônima, em benefício dos que sofrem (A medicina..., 1 out. 1936).

\section{O imbróglio}

Infelizmente, A medicina no interior causou também desagradável dor de cabeça a seu autor por causa da confusão gerada entre seu nome e de seu renomado homônimo. Exemplo disso foi o artigo "O médico na aldeia", de Jair Silva, publicado na Folha de Minas, em 4 de novembro de 1936:

Lendo em alemão e conversando em português com os caipiras e os coronéis, o sr. Manoel de Abreu não é médico da roça pela lógica dos acontecimentos. Ele próprio escolheu o lugar para o seu consultório. Talvez desejasse evitar os doentes pernósticos da metrópole, com a sua exposição de males ensaiada, e as polêmicas da Sociedade de Medicina e Cirurgia. Enfim, o sr. Manoel de Abreu não tem nada de médico da roça, a não ser o pseudônimo de 'dr. Campanario', que não devia aparecer em trabalho de tanta utilidade. O seu pseudônimo escandaliza como rabo de papel em smoking. Não deve mais usá-lo. E aqui está o melhor elogio que lhe faço... Jogando fora o pseudônimo, que absolutamente não lhe convém, o sr. Manoel de Abreu poderá ser professor de medicina e conferencista nas capitais (Silva, 4 nov. 1936; destaques no original).

O imbróglio fez com que o criador da abreugrafia remetesse uma declaração-consulta à Sociedade de Medicina e Cirurgia, que decidiu instalar uma comissão com o propósito de apurar o caso. Em O Jornal, de 17 de junho de 1937, a Sociedade de Medicina e Cirurgia torna público o parecer da comissão. Os subtítulos da coluna foram: "Solucionado o caso dos homônimos Manoel de Abreu - Parecer da comissão - Carta esclarecedora - As comunicações".

o dr. Peregrino Junior relatou o parecer da Comissão incumbida de examinar o caso suscitado com o aparecimento do livro A medicina no interior, do dr. Campanario (Manoel de Abreu), cujo autor é homônimo do conhecido radiologista professor Manoel de Abreu. 


\section{Sociedade de Medicina e Cirurgia}

\section{Solucionado o caso dos homonynos Manoel de Abreu - Parecer da commissão - Carta esclarecedora - As communicações}

Esteve reunida $3 c b$ a presidencia do professor Helion Povoa, a Sociedade de Medicina e Crurgia.

Tendo se extinguido o prazo para a entrega dos trabalhos cancurrentes ao premie de $10: 000 \$ 000$ para a melher cartilha sobre alimentaçāo, ficou assim constituida commissão julgadora dos mesmos: professor Helion Povoa, como presidente da Sociedade de Medicina e Cirurgia; professores: Afranio Peizoto, Annes Dias e os drs. Alexandre Moscoso e Arthur de Vasconcellos.

\section{o pafecer da combissao}

A seguir, o dr. Peregrino Junior relatou o parecer da Commisão: incumbida de examinar o caso suscitado com o apparecimento do livio "A medicina no interior" do dr. Campanario (Manoel de Abreu), cujo autor é homonymo do conhecido radiologista professor Mcnoe! de Abieu.

o parecer examina o caso dentio das regras severas da boa ethira. Acha tolavia, que, incidentes desta order' muita vez, nào nascem de unna $i$ i:ienção deliberada sendo frequentc iente fruto do pthics. Acha, toda iq, que, incinue e attenua a cilpa de quem commette a infracçào.

No caso em aprecco, diz o parecer, talvez occorra esta ultima hypothese.

O dr. Campanario (Manoel de Abreu), certamente, tendo verificedo o incidente, seja o primeiro B collocar o seu nome por extenso nos proximos livros, para prudentemente evitar equivocos e confusóes. Comtudo, continua o parecer, Manoel de Abreu, militando na sciencia nas letras desde 1318, com brilho singular e pessoal é de si inconfundivel e os leitores, de certo, com o poder de discernimento e de critica que devem ter, hão de saber distinguir sem esforco onde está o escriptor legitimo e a contrấaccão

Continuando, o parecer lamenta o incidente e propóe que a Socie. dade formule um appello aos collegas que tém homonymos illustres de nome conhecido conceituado, para que evitem, o que será facil, os equivoces e a confusóes das coincidencias desta categoria. Concluindo, diz que no caso em apreco, felizmente, o incidente $\dot{e}$ inexistente em virtude da attitude do di. Campanario (Mannel de Abreu) qie escreveu a respeito una carta apresentando exulicaçōes ao professor Manoel de Abreu.

\section{A CARTA ESCLARECEDOR.A}

Damos a seguir o texio da carta cnviada an professor Manoel de Abreu, pelo sr. Campanario (Manoel de Abreu):
"Presado collega prof. तr. Manoel de Abreu. - Fio. - Saudaços.

No o Jon.i.t do dia de hoje tive a opportunidade de ler a sua "declaracán-consulta" feita á Sociedade de Medicina e Cirurgia.

passo a dar-lhe os esclarecimentos necessarios ao caso: o meu nome é Manoel de Abreu Campanario. No emianto, sou conhecido por todos. inclusive pelos collegas, por Dr. Campanario, e, por isto, descie a épóca da minha formatura (1931) até a presenle data o cabegalho das minhas receitas medicas é este: I)r. Campanario (Manoel de Abreu).

Lamento immensamente que o prof., tomando o nome Campanario por pseudonymo, me julgasse capaz de proecder tão indignamente. Confusăo entre o seu flustlre nome e o da minha bumilde pessoa, penso, jamals buuve, não hil, nem haverá.

Pela propria humildade do titulo di meu livro "A Medicina no Interior" qualquer medico deduz loge que o dr. Campanario trabalha na roşa c, ao certo, nunca fará confusão de tal nome coin o do radiologista prof. Manoel de Abreu. Isto é losico. A minha culpa, presado prof. se $\dot{e}$ que existe, foi ter o nome parecido com o sell.

Lamento tambem nảo ter recebido carta, telephonema ou qua!quer outra communieação da sua partes, o que o prof. poderia facilmente ter feito por intermedio do editor $\mathrm{C}_{2}$ lvino Filho que, aliás. tambem è medico. Isto certamente teria evitado a injusta accusasão que recebi com profunda magua, dado o meu feitio moral. Julgo mais do que necessario que o senhor leve estas minhas palairas até aos dignos membros da Sociedade de Medicina, afim de que todos saibam que o dr. Manoel de Abreu Campariario, de Padua, Estado do Rio, dentro do terreno profissional. acima de tudo ama as "normas da boa ethica". Espero tambem que o senhor ou a Sociedade de Medicina dê ao O JORNAl uma nota esclarecedora do ca. so, evitando, deste modo, o commentario tortuoso de lerceiros.

Aguardando a sua boa attenção subscrevo-me de sua pessoa." etc.

A seguir, ainda no expédionte, o dr. Pitanga Santos offereceu á Sociedade um premio de $2: 000 \$ 000$, doado pela casa Bayer e destinado no socio que maior numero de cummunicaçōes scientificas apresentar no decorrer do anno.

Seguiu-se a orden do dia com uma communicaçáo do professor David Sanson sobre alguns easos de plastica e outra do dr. Pitanga Santos sobre estrangulamento hemorroidario.

Figura 4: Fragmento de O Jornal de 17 de junho de 1937 
O parecer examina o caso dentro das regras severas da boa ética. Acha, todavia, que incidentes desta ordem, muita vez, não nascem de uma intenção deliberada...

O dr. Campanario (Manoel de Abreu), certamente, tendo verificado o incidente, seja o primeiro a colocar o seu nome por extenso nos próximos livros, para prudentemente evitar equívocos e confusões. Contudo, continua o parecer, Manoel de Abreu, militando na ciência e nas letras desde 1918, com brilho singular e pessoal é de si inconfundível, e os leitores, decerto, com o poder de discernimento e de crítica que devem ter, hão de saber distinguir sem esforço onde está o escritor legítimo e a contrafação.

Continuando, o parecer lamenta o incidente e propõe que a sociedade formule um apelo aos colegas que têm homônimos ilustres de nome conhecido e conceituado, para que evitem, o que será fácil, os equívocos e as confusões das coincidências dessa categoria. Concluindo, diz que no caso em apreço, felizmente, o incidente é inexistente em virtude da atitude do dr. Campanario (Manoel de Abreu), que escreveu a respeito uma carta esclarecedora apresentando explicações ao professor Manoel de Abreu (Sociedade..., 17 jun. 1937).

Na carta enviada ao professor Manoel de Abreu, Campanario dá seu ponto de vista sobre a confusão:

O meu nome é Manoel de Abreu Campanario. No entanto, sou conhecido por todos, inclusive pelos colegas, por dr. Campanario, e, por isso, desde a época da minha formatura (1931) até a presente data, o cabeçalho das minhas receitas médicas é este: dr. Campanario (Manoel de Abreu).

Lamento imensamente que o professor, tomando o nome Campanario por pseudônimo, me julgasse capaz de proceder tão indignamente. Confusão entre o seu ilustre nome e o da minha humilde pessoa, penso, jamais houve, não há, nem haverá.

Pela própria humildade do título do meu livro A medicina no interior, qualquer médico deduz logo que o dr. Campanario trabalha na roça e, ao certo, nunca fará confusão de tal nome com o do radiologista professor Manoel de Abreu. Isso é lógico. A minha culpa, prezado professor, se é que existe, foi ter o nome parecido com o seu (Sociedade..., 17 jun. 1937).

Em seguida, critica sutilmente a forma como seu homônimo conduziu o caso:

Lamento também não ter recebido carta, telefonema ou qualquer outra comunicação da sua parte, o que o professor poderia facilmente ter feito por intermédio do editor Calvino Filho, que, aliás, também é médico. Isso certamente teria evitado a injusta acusação que recebi com profunda mágoa, dado o meu feitio moral (Sociedade..., 17 jun. 1937).

Esclarecido o caso, convém destacar, ainda que resumidamente, a contribuição dos dois médicos para a medicina brasileira. De um lado, um obstinado Manoel Dias de Abreu, capaz de vislumbrar a aplicação social da radiologia, não descansou até tornar possível o diagnóstico em massa de importante enfermidade da primeira metade do século XIX - a tuberculose. De outro lado, Campanario, ainda jovem, retratou a pobreza do Brasil rural de então e as dificuldades do exercício da medicina naquelas condições, além de antecipar discussões que paulatinamente ganhariam destaque nos anos vindouros, tais como a eutanásia, o aborto, as incongruências do ensino médico, a especialização precoce e o aparente descaso com a clínica geral. 


\section{NOTA}

* Este trabalho recebeu o Prêmio "José da Almeida Camargo" de Cultura Geral do Departamento Científico da Associação Paulista de Medicina em 2001.

\section{REFERÊNCIAS}

A MEDICINA...

A medicina no interior: um livro interessante do dr. Manoel de Abreu Campanario. O Estado, 1 out. 1936.

ABREU, Manoel de.

Röntgen-photografia. Revista da Associação Paulista de Medicina, v.9, n.6, p.313-323. dez. 1936.

ABREU, Manoel de.

Radiodiagnostic dans la tuberculose pleuropulmonaire. Paris: Masson. 1921.

BEDRIKOW, Rubens.

Manoel de Abreu. Jornal Brasileiro de Pneumologia, v.27, n.1, p.56-58. jan.-fev. 2001.

BEDRIKOW, Rubens.

Entrevista com Marília Campanario, filha de Manoel de Abreu Campanario. (Acervo pessoal de Rubens Bedrikow, São Paulo). 20 set. 2000.

CAMPANARIO, Manoel de Abreu.

Curriculum vitae de Manoel de Abreu

Campanario. (Acervo pessoal de Rubens

Bedrikow, São Paulo). 18 out. 1991.

CAMPANARIO, Manoel de Abreu.

Hans Staden: o homem e a obra. São Paulo: Parma. 1980.

CAMPANARIO, Manoel de Abreu.

Acerca do relatório radiológico. Revista Paulista de Medicina, v.51, p.400-408. nov. 1957.

CAMPANARIO, Manoel de Abreu. A medicina no interior. Belo Horizonte: [s.n.]. 1936.

DR. MANOEL...

Dr. Manoel de Abreu Campanario. Jornal da Imagem, n.160, p.39-40. dez. 1991.
ISCMSP.

Irmandade da Santa Casa de Misericórdia de São Paulo. Ata da sessão da Mesa Administrativa, São Paulo. 5 fev. 1962.

MELO, Antônio Silva.

Carta a Manoel de Abreu Campanario. (Acervo pessoal de Marília Campanario, Rio de Janeiro). 16 jun. 1937.

SALGADO, Plínio.

Carta a Manoel de Abreu Campanario. (Acervo pessoal de Marília Campanario, Rio de Janeiro). 28 jun. 1937.

SANTOS, Itazil Benício dos.

Vida e obra de Manoel de Abreu: o criador da abreugrafia. Rio de Janeiro: Irmãos Pongetti Editores. 1963.

SILVA, Jair.

O médico na aldeia. Folha de Minas, 4 nov. 1936.

SOCIEDADE...

Sociedade de Medicina e Cirurgia. Solucionado o caso dos homônimos Manoel de Abreu. O Jornal, 17 jun. 1937.

VERGARA, Luiz.

Carta a Manoel de Abreu Campanario. (Acervo pessoal de Marília Campanario, Rio de Janeiro). 22 set. 1936.

VIANNA, Baeta.

Carta a Manoel de Abreu Campanario. (Acervo pessoal de Marília Campanario, Belo Horizonte). 1 jul. 1936.

VIEIRA, Celso.

Dr. Campanario. A Noite, 25 set. 1936.

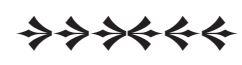

